\title{
Chronic hypoxia increases rat diaphragm muscle endurance and sodium-potassium
} ATPase pump content

\author{
C. McMorrow*, A. Fredsted ${ }^{\#}$, J. Carberry*, R.A. O’Connell*, A. Bradford", \\ J.F.X. Jones* and K.D. O'Halloran*
}

ABSTRACT: The effects of chronic hypoxia $(\mathrm{CH})$ on respiratory muscle are poorly understood. The aim of the present study was to examine the effects of $\mathrm{CH}$ on respiratory muscle structure and function, and to determine whether nitric oxide is implicated in respiratory muscle adaptation to $\mathrm{CH}$.

Male Wistar rats were exposed to $\mathrm{CH}$ for 1-6 weeks. Sternohyoid and diaphragm muscle contractile properties, muscle fibre type and size, the density of fibres expressing sarco/ endoplasmic reticulum calcium-ATPase (SERCA) 2 and sodium-potassium ATPase $\left(\mathrm{Na}^{+}, \mathrm{K}^{+}-\right.$ ATPase) pump content were determined. Muscle succinate dehydrogenase (SDH) and reduced nicotinamide adenine dinucleotide phosphate (NADPH) dehydrogenase activities were also assessed. Acute and chronic blockade of nitric oxide synthase (NOS) was employed to determine whether or not $\mathrm{NO}$ is critically involved in functional remodelling in $\mathrm{CH}$ muscles.

$\mathrm{CH}$ improved diaphragm, but not sternohyoid, fatigue tolerance in a time-dependent fashion. This adaptation was not attributable to increased SDH or NADPH dehydrogenase activities. The areal density of muscle fibres and relative area of fibres expressing SERCA2 were unchanged. $\mathrm{Na}^{+}, \mathrm{K}^{+}$-ATPase pump content was significantly increased in $\mathrm{CH}$ diaphragm. Chronic NOS inhibition decreased diaphragm $\mathrm{Na}^{+}, \mathrm{K}^{+}$-ATPase pump content and prevented $\mathrm{CH}$-induced increase in muscle endurance.

This study provides novel insight into the mechanisms involved in $\mathrm{CH}$-induced muscle plasticity. The results may be of relevance to respiratory disorders characterised by $\mathrm{CH}$, such as chronic obstructive pulmonary disease.

KEYWORDS: Chronic obstructive pulmonary disease, fatigue, myosin heavy chain isoforms, nitric oxide synthase, sarco/endoplasmic reticulum calcium-ATPase 2

keletal muscle has enormous capacity for remodelling, as evident in various physiological and pathophysiological settings. Chronic hypoxia $(\mathrm{CH})$, a feature of respiratory disease, is known to affect skeletal muscle structure and function. Alterations include changes in capillarity [1, 2], fibre size and distribution [3-10], oxidative capacity $[5,6,11,12]$ and contractile performance $[5,9,13-16]$. $\mathrm{CH}$ induces reflex hyperventilation. Thus respiratory muscles are unique in that they must increase their workload in the face of a reduction in oxygen availability, necessary for aerobic metabolism. Respiratory muscle remodelling is a feature of chronic obstructive pulmonary disease (COPD) [17-27], which may be the result of hypoxic adaptation. Surprisingly, there is a general paucity of information concerning the effects of $\mathrm{CH}$ on respiratory muscle structure and function despite the clinical relevance. Translational animal models permit examination of the effects of $\mathrm{CH}$ on skeletal muscle independent of other confounding factors that are present in disease. Furthermore, they permit a thorough exploration of the molecular mechanisms that underpin muscle adaptation. As such, the major aim of the present study was to conduct a comprehensive assessment of respiratory muscle properties in an animal model of $\mathrm{CH}$.

We sought to examine the effects of $\mathrm{CH}$ on rat respiratory pump and upper airway muscle contractile and endurance properties, fibre type and size, oxidative enzyme activity, relative area of

\section{AFFILIATIONS}

*University College Dublin School of Medicine and Medical Science, Health Sciences Centre, University College Dublin, and

"Dept of Physiology and Medical Physics, Royal College of Surgeons in Ireland, Dublin, Ireland. \#Dept of Physiology and Biophysics, Aarhus University, Aarhus, Denmark.

CORRESPONDENCE

K.D. O'Halloran

University College Dublin School of

Medicine and Medical Science,

C228 Health Sciences Centre

University College Dublin

Belfield

Dublin 4

Ireland

E-mail: ken.ohalloran@ucd.ie

Received:

May 212010

Accepted after revision:

Nov 012010

First published online:

Dec 092010 
fibres expressing sarco/endoplasmic reticulum calcium ATPase (SERCA) 2 and sodium-potassium ATPase $\left(\mathrm{Na}^{+}, \mathrm{K}^{+}\right.$-ATPase) pump content. SERCAs are responsible for a significant proportion of energy consumption in skeletal muscle, second only to myosin ATPase. Muscle endurance correlates with SERCA function, especially that of the SERCA2 isoform [28], and a fast-to-slow SERCA transformation has been reported in COPD diaphragm [29]. The $\mathrm{Na}^{+}, \mathrm{K}^{+}$-ATPase pump plays a dynamic role in the maintenance of myocyte excitability during contractile activity [30, 31]. $\mathrm{Na}^{+}, \mathrm{K}^{+}$-ATPase pump function is extremely malleable and readily adapts to a variety of stimuli, including hormones, electrolytes, diet, contractile activity and hypoxia [32]. Skeletal muscles express all three isoforms of nitric oxide synthase (NOS), and nitric oxide is implicated in skeletal muscle adaptation in health and disease. Therefore, it was explored whether NO is critically involved in $\mathrm{CH}$-induced respiratory muscle plasticity. It was hypothesised that: 1) $\mathrm{CH}$ affects respiratory muscle function in a timedependent fashion; 2) $\mathrm{CH}$ causes structural and metabolic adjustments in respiratory muscle leading to functional remodelling; 3) $\mathrm{CH}$ alters respiratory muscle $\mathrm{Na}^{+}, \mathrm{K}^{+}$-ATPase content; and 4) NOS inhibition prevents $\mathrm{CH}$-induced functional plasticity in respiratory muscle.

\section{METHODS}

Full details of the methods are provided in the online supplementary material.

\section{Animals}

Experiments were performed on 72 adult male Wistar rats. $\mathrm{CH}$ groups were placed in a hypobaric chamber for 1-6 weeks at $380 \mathrm{mmHg}$ (ambient oxygen tension $\sim 80 \mathrm{mmHg}$, equivalent to an inspiratory oxygen fraction of $10.5 \%$ ). Age- and weightmatched control animals were held in parallel at ambient atmospheric pressure $(\sim 760 \mathrm{mmHg})$.

\section{Effects of $\mathrm{CH}$ on respiratory muscle function}

Rats were exposed to normoxia or $\mathrm{CH}$ for 1, 2, 3 and 6 weeks. Sternohyoid and diaphragm muscle contractile and endurance properties were determined in vitro. Respiratory and limb muscles from normoxic and $\mathrm{CH}$ animals were snap frozen and stored at $-80^{\circ} \mathrm{C}$.

\section{SDH and reduced NADPH dehydrogenase histochemistry in respiratory and limb muscles}

The succinate dehydrogenase (SDH) and reduced nicotinamide adenine dinucleotide phosphate (NADPH) dehydrogenase activity of respiratory and limb muscles were determined. Normoxic and $\mathrm{CH}$ muscle sections were processed in parallel.

\section{Myosin heavy chain immunohistochemistry in respiratory and limb muscles}

Indirect immunofluorescence was performed to determine myosin heavy chain (MHC) isoform composition. Normoxic and $\mathrm{CH}$ muscle sections were incubated with a cocktail of primary antibodies that targeted $\mathrm{MHC}$ type $1,2 \mathrm{~A}$ and $2 \mathrm{~B}$ fibres or a primary antibody that targeted all of the isoforms but MHC type $2 X$.

\section{SERCA immunohistochemistry in diaphragm muscle}

Indirect immunofluorescence determination of the SERCA2 isoform was performed on normoxic and $\mathrm{CH}$ diaphragms.

\section{Measurement of the content of $\left[{ }^{3} \mathrm{H}\right]$ ouabain binding sites, and $\mathrm{Na}^{+}, \mathrm{K}^{+}$and $\mathrm{Ca}^{2+}$ in muscle}

Respiratory and limb muscle content of the $\mathrm{Na}^{+}, \mathrm{K}^{+}$-ATPase pump $\alpha_{2}$-isoform was determined using the vanadate-facilitated $\left[{ }^{3} \mathrm{H}\right]$ ouabain binding method $[33,34]$. Additionally, muscle $\mathrm{Na}^{+}, \mathrm{K}^{+}$(flame photometry) and $\mathrm{Ca}^{2+}$ (atomic absorption spectrophotometry) content were determined.

\section{Effect of chronic NOS inhibition on diaphragm muscle structure and function}

In a separate series of experiments, structural and functional assessments were performed on diaphragm muscle from rats treated chronically with $N^{\omega}$-nitro-L-arginine (L-NNA; $2 \mathrm{mM}$ in the drinking water), commencing 3 days before normoxia or $\mathrm{CH}$ treatment and continuing throughout a 6-week treatment period.

\section{Data analysis}

Specific force was calculated in newtons per square centimetre of muscle cross-sectional area (CSA). Fatigue tolerance was determined. In order to determine SDH and NADPH dehydrogenase activity, the optical density of muscle sections was calculated using Scion Image $\mathrm{e}^{\mathrm{TM}}$ software (Scion Corporation, Frederick, MD, USA). For immunofluorescence analysis, Cell $\mathrm{A}^{\mathrm{TM}}$ software (Olympus Life Science Microscopes, Munich, Germany) was used to digitally analyse images and calculate numerical and areal density and CSA for each MHC fibre type. The relative area of diaphragm fibres containing SERCA2 was calculated. All data were averaged per animal before computing group means. Data are expressed as mean \pm SEM. Data were compared across groups by one-way (hypoxia), two-way (hypoxia $\times$ drug) or three-way (hypoxia $\times$ drug $\times$ frequency or time) ANOVA as appropriate. Some datasets were compared using unpaired t-tests when appropriate. In all tests, a p-value of $<0.05$ was taken as significant.

\section{RESULTS}

\section{Body mass, haematocrit and right ventricular mass}

$\mathrm{CH}$ exposure for 1, 2, 3 and 6 weeks significantly decreased body mass compared to that of age-matched normoxic controls (table 1 of online supplementary material). Haematocrit and right ventricular mass were significantly elevated in all hypoxic groups (table 1 of online supplementary material). Left ventricular mass (normalised to body mass) was unaffected by $\mathrm{CH}$ (data not shown).

\section{Muscle physiology}

The effects of $\mathrm{CH}$ (1-6 weeks) on sternohyoid and diaphragm twitch and peak tetanic force, contraction time and halfrelaxation time are shown in table 2 of the online supplementary material. Data for the 6-week exposure are shown in table 1. $\mathrm{CH}$ had no significant effect on the force-frequency relationship in the sternohyoid, but $\mathrm{CH}$ decreased diaphragm muscle force (table 1 of the online supplementary material; fig. 1 of the online supplementary material). $\mathrm{CH}$ had no effect on sternohyoid muscle endurance (fig. 1) (fig. 2 of the online supplementary material). Conversely, $\mathrm{CH}$ increased diaphragm 


\begin{tabular}{|c|c|c|}
\hline & $P \mathrm{t} \mathrm{N} \cdot \mathrm{cm}^{-2}$ & $P_{0} \mathrm{~N} \cdot \mathrm{cm}^{-2}$ \\
\hline \multicolumn{3}{|l|}{ Sternohyoid } \\
\hline Normoxia & $3.3 \pm 0.4$ & $14.4 \pm 1.2$ \\
\hline $\mathrm{CH}$ & $2.5 \pm 0.3$ & $15.6 \pm 0.7$ \\
\hline \multicolumn{3}{|l|}{ Diaphragm } \\
\hline Normoxia & $4.0 \pm 0.7$ & $20.0 \pm 2.3$ \\
\hline $\mathrm{CH}$ & $2.8 \pm 0.4$ & $14.2 \pm 1.8^{\#}$ \\
\hline \multicolumn{3}{|c|}{$\begin{array}{l}\text { Data are presented as mean } \pm \text { SEM ( } n=6 \text { for all groups). Pt: single-twitch tension; } \\
\text { Po: peak tetanic tension; } \mathrm{CH} \text { : chronic hypoxia ( } 6 \text { weeks). }{ }^{\#}: \mathrm{p}=0.08 \text { (unpaired } \\
\text { t-test). }\end{array}$} \\
\hline
\end{tabular}

endurance (fig. 1) (figs. 2 and 3 of the online supplementary material). The magnitude of the improved fatigue tolerance was greatest after 6 weeks of $\mathrm{CH}$ (fig. 2 of the online supplementary material).

\section{MHC isoform composition and fibre morphometry}

Representative MHC immunofluorescence images are shown in figure 2. $\mathrm{CH}$ increased the numerical density of MHC type 1 fibres in diaphragm, but this failed to reach statistical significance ( $33 \pm 2$ versus $39 \pm 3 \% ; p=0.09$ (unpaired t-test)). $\mathrm{CH}$ decreased diaphragm MHC type 1 , type $2 \mathrm{X}$ and type $2 \mathrm{~B}$ CSA (table 2). CH generally decreased or had no effect on fibre CSAs in the other muscles analysed, although hypertrophy of type $2 \mathrm{~A}$ and type $2 \mathrm{X}$ fibres was observed in the sternohyoid (table 2). Areal density for MHC protein-determined fibre types are shown in table 2. There was no significant effect of $\mathrm{CH}$ on areal density of fibre types (table 2), and little or no change in the sternohyoid (table 2), soleus and extensor digitorum longus (EDL) muscles (data not shown).

\section{SERCA2 immunohistochemistry}

There was no significant difference in the areal density of fibers expressing SERCA2 between control and $\mathrm{CH}$ diaphragms (fig. 3).

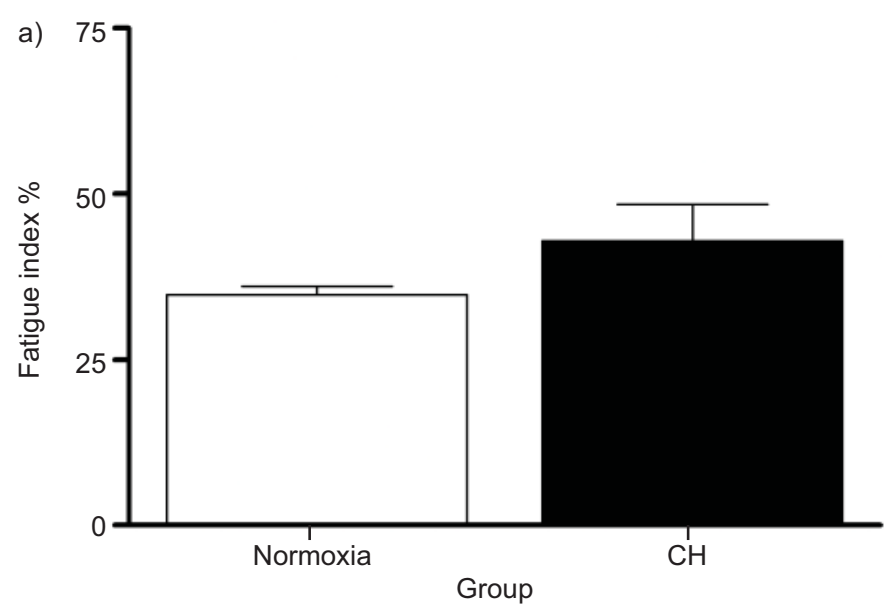

\section{SDH and NADPH dehydrogenase activities}

There was no significant difference in SDH or NADPH dehydrogenase activity between control and $\mathrm{CH}$ respiratory muscles (table 3). Similarly, $\mathrm{CH}$ did not affect limb muscle enzyme activities (data not shown). Optical densities were highest in the diaphragm and lowest in the sternohyoid (diaphragm $>$ soleus $>$ EDL $>$ sternohyoid).

\section{$\mathrm{Na}^{+}, \mathrm{K}^{+}$-ATPase pump content and diaphragm muscle ionic content}

$\mathrm{CH}$ caused a significant increase in diaphragm (fig. 4) and EDL $\mathrm{Na}^{+}, \mathrm{K}^{+}$-ATPase pump content, but had no effect on pump content in the sternohyoid and the soleus (table 3 of online supplementary material). $\mathrm{CH}$ significantly increased $\mathrm{K}^{+}$content in the diaphragm (table 4).

\section{Effects of chronic NOS inhibition on diaphragm structure and function}

Chronic inhibition of NOS decreased peak force in normoxic, but not $\mathrm{CH}$, diaphragms (fig. 4 of online supplementary material). Chronic NOS blockade had no effect on diaphragm oxidative capacity. There were no major effects of chronic NOS inhibition on diaphragm MHC areal density measurements. Chronic NOS inhibition did not affect $\mathrm{CH}$-induced atrophy of diaphragm type 1 and type $2 X$ fibres (table 4 of online supplementary material). However, chronic NOS inhibition decreased diaphragm $\mathrm{Na}^{+}, \mathrm{K}^{+}$-ATPase pump content (fig. 4) and prevented the $\mathrm{CH}$-induced increase in fatigue tolerance (fig. 5).

\section{DISCUSSION}

The major findings of the present study are: 1) $\mathrm{CH}$ improves diaphragm muscle endurance; 2) $\mathrm{CH}$-induced muscle plasticity is time-dependent and differentially expressed in respiratory muscles; 3) $\mathrm{CH}$ does not increase diaphragm SDH or NADPH dehydrogenase activities; 4) $\mathrm{CH}$ does not alter respiratory or limb $\mathrm{MHC}$ areal density; 5) $\mathrm{CH}$ does not increase the relative area of diaphragmatic fibres expressing SERCA2; 6) $\mathrm{CH}$ increases $\mathrm{Na}^{+}, \mathrm{K}^{+}$-ATPase pump content in diaphragm; and 7) chronic NOS blockade decreases diaphragm $\mathrm{Na}^{+}, \mathrm{K}^{+}$-ATPase content and prevents $\mathrm{CH}$-induced functional remodelling in the diaphragm.

b)

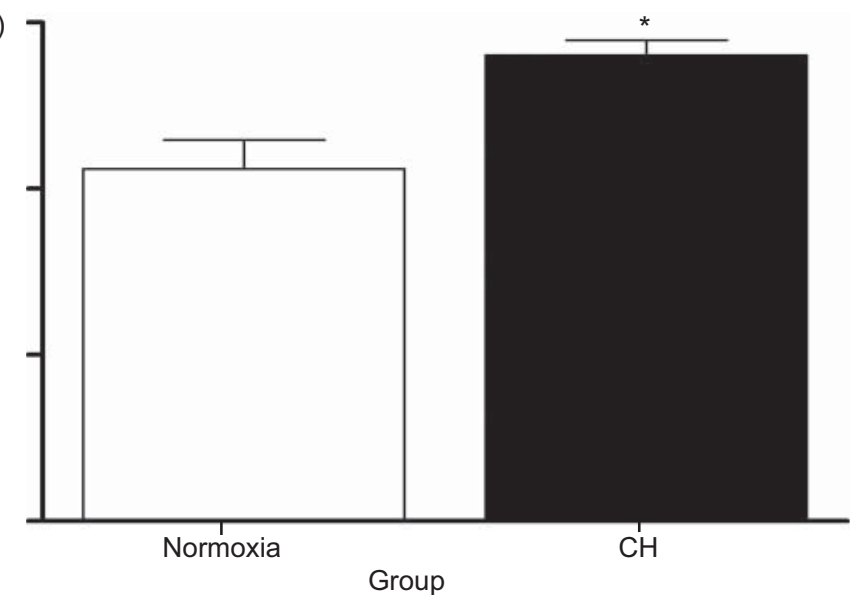

FIGURE 1. Effect of chronic hypoxia $(\mathrm{CH})$ on respiratory muscle fatigue, based on initial force, in a) sternohyoid and b) diaphragm. Data are presented as mean $\pm \mathrm{SEM}$ ( $\mathrm{n}=6$ for all groups) in adult rats exposed to 6 weeks of normoxia or $\mathrm{CH}$. *: $\mathrm{p}<0.05$ versus normoxia (unpaired $\mathrm{t}$-test). 
Diaphragm
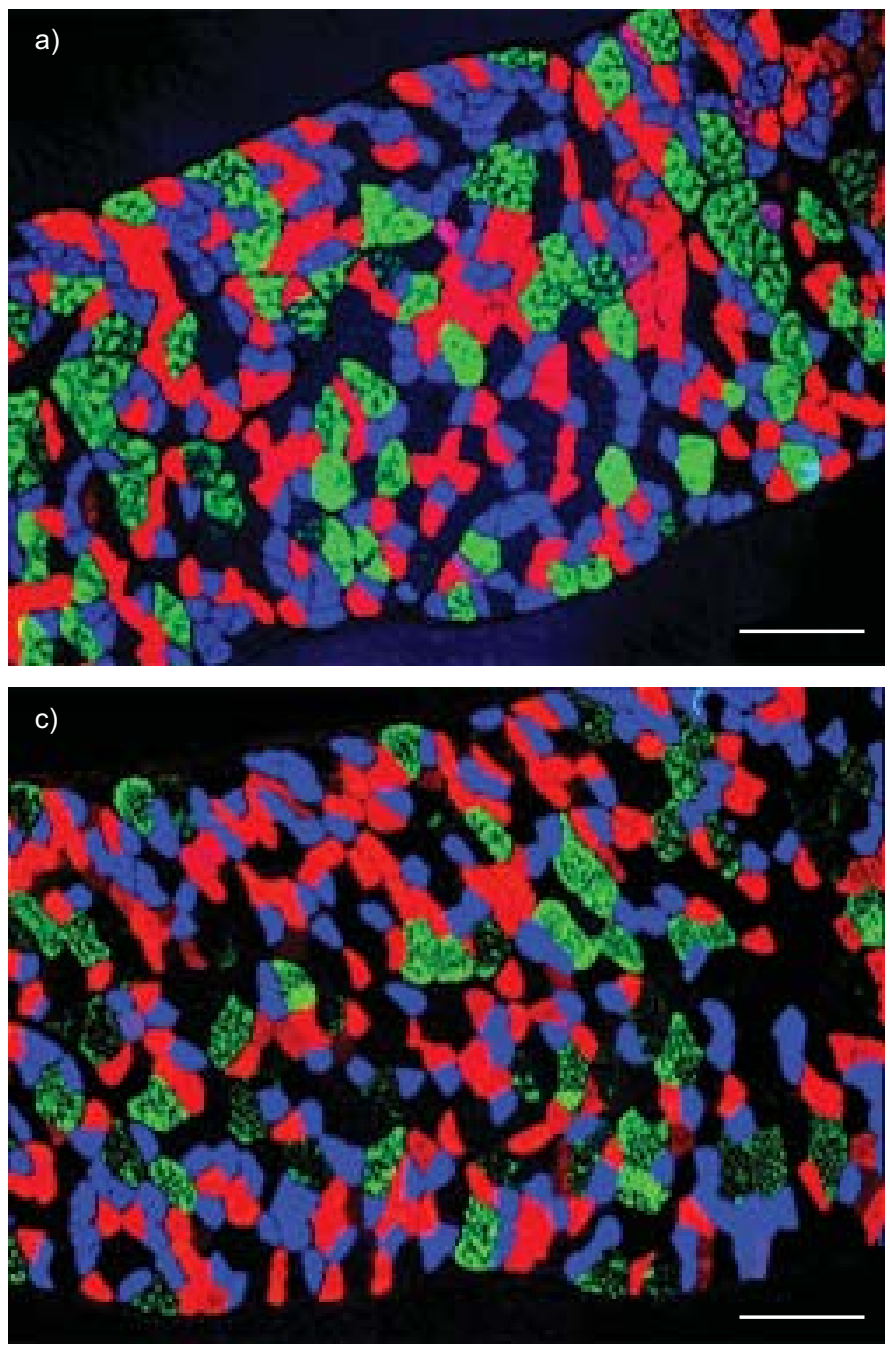

Sternohyoid
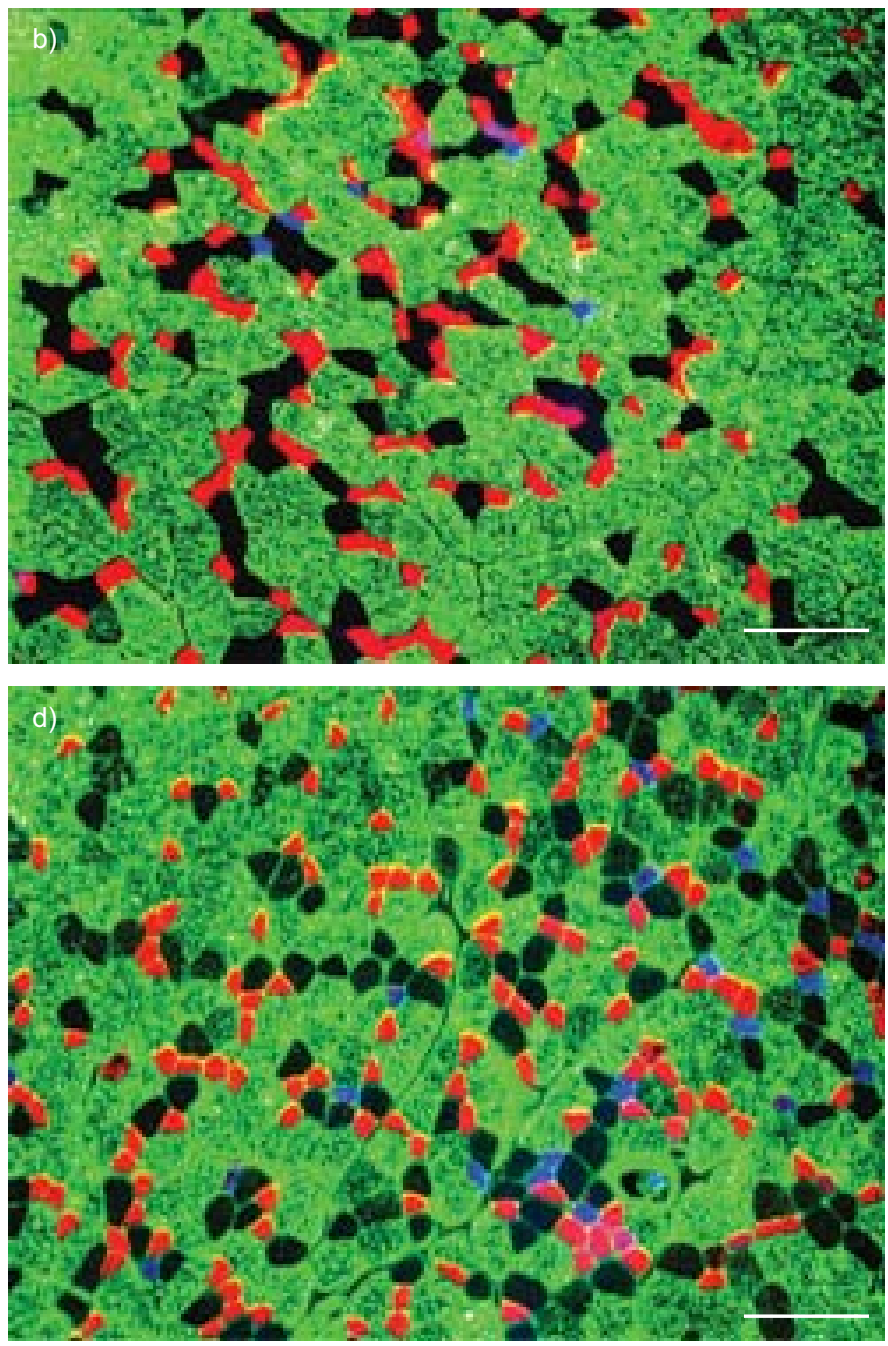

FIGURE 2. Myosin heavy chain (MHC) immunohistochemistry in rat respiratory muscles. Triple-labelling of muscle fibres in a, b) normoxic and c, d) chronic hypoxic rat;

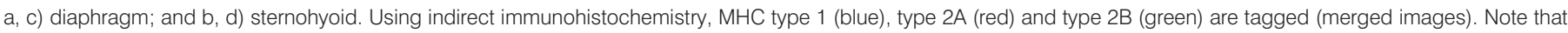
the sternohyoid muscle shows a higher complement of MHC type $2 \mathrm{~B}$ fibres than the diaphragm. Scale bars $=200 \mu \mathrm{m}$.

\section{$\mathrm{CH}$-induced functional remodelling}

Few have studied the effects of $\mathrm{CH}$ on the respiratory muscles [13-16], which is surprising since alterations to respiratory muscle function at altitude or in diseases characterised by hypoxia could have consequences for respiratory homeostasis. $\mathrm{CH}$ decreased diaphragm force, a finding consistent with some $[13,14]$ but not other reports $[15,16]$. $\mathrm{CH}$ improved diaphragm endurance, which contrasts with the findings of previous studies $[13,15,16]$. It could be speculated that differences in the intensity of the hypoxic challenges, as well as differences in the experimental paradigms employed when studying muscle function, contribute, at least in part, to this apparent discrepancy.

$\mathrm{CH}$ had differential effects on sternohyoid and diaphragm function. The different structural and metabolic profiles of these muscles may explain why endurance was enhanced in the diaphragm and not in the sternohyoid. It is plausible that reduced oxygen availability triggers adaptive mechanisms in skeletal muscle of high oxidative capacity since these muscles are heavily reliant on oxygen to generate energy. In contrast, perturbations in oxygen supply to muscles with a lower oxidative capacity may not trigger such adaptive mechanisms. It is interesting to note that differential effects of $\mathrm{CH}$ have also been reported in limb muscles of varying structural phenotype $[5,15]$. This suggests that the effects of $\mathrm{CH}$ on muscle function may be dependent upon the intrinsic structure, metabolism and physiological function of individual muscle types.

It was hypothesised that functional remodelling would proceed gradually in a time-dependent manner during $\mathrm{CH}$ exposure, and the results of the present study support this notion. The reason for the differential effect of $\mathrm{CH}$ on sternohyoid and diaphragm muscle endurance remains unclear, but, in light of the present findings with chronic NOS blockade (see below), fibre-specific differences in NOS expression and activity may have been a contributing factor [35-37]. NOS activity is highest in fast oxidative fibres, which are considerably more abundant in diaphragm than in sternohyoid muscle. As such, the diaphragm may possess greater capacity for NO-dependent functional remodelling than other muscles. 


\begin{tabular}{|c|c|c|c|c|c|}
\hline \multirow[t]{2}{*}{ TABLE 2} & \multicolumn{5}{|c|}{$\begin{array}{l}\text { Respiratory muscle myosin heavy chain (MHC) } \\
\text { areal density and fibre cross-sectional area } \\
\text { (CSA) }\end{array}$} \\
\hline & & Type 1 & Type 2A & Type 2X & Type 2B \\
\hline \multicolumn{6}{|l|}{ Sternohyoid } \\
\hline \multicolumn{6}{|c|}{$\begin{array}{l}\text { MHC isoform areal } \\
\text { density \% }\end{array}$} \\
\hline Normoxia & & $0.52 \pm 0.10$ & $14.1 \pm 1.4$ & $7.3 \pm 1.0$ & $77.2 \pm 2.2$ \\
\hline $\mathrm{CH}$ & & $0.49 \pm 0.20$ & $13.6 \pm 1.2$ & $11.0 \pm 1.2$ & $77.1 \pm 1.5$ \\
\hline \multicolumn{6}{|c|}{ Fibre CSA $\mu \mathrm{m}^{2}$} \\
\hline Normoxia & & $993 \pm 64$ & $1192 \pm 31$ & $1999 \pm 43$ & $3792 \pm 64$ \\
\hline $\mathrm{CH}$ & & $891 \pm 44$ & $1489 \pm 52^{*}$ & $2235 \pm 70^{*}$ & $3834 \pm 53$ \\
\hline \multicolumn{6}{|l|}{ Diaphragm } \\
\hline \multicolumn{6}{|c|}{$\begin{array}{l}\mathrm{MHC} \text { isoform areal } \\
\text { density \% }\end{array}$} \\
\hline Normoxia & & $21.8 \pm 1.7$ & $24.3 \pm 2.1$ & $27.8 \pm 4.0$ & $19.1 \pm 4.4$ \\
\hline $\mathrm{CH}$ & & $25.3 \pm 2.7$ & $22.0 \pm 1.3$ & $25.5 \pm 3.1$ & $26.9 \pm 6.1$ \\
\hline \multicolumn{6}{|c|}{ Fibre CSA $\mu \mathrm{m}^{2}$} \\
\hline Normoxia & & $1410 \pm 38$ & $1422 \pm 26$ & $2565 \pm 80$ & $5024 \pm 177$ \\
\hline $\mathrm{CH}$ & & $1232 \pm 25^{\star}$ & $1384 \pm 23$ & $2040 \pm 75^{\star}$ & $3424 \pm 85^{*}$ \\
\hline
\end{tabular}

Data are presented as mean \pm SEM ( $n=8-11$ per group). $\mathrm{CH}$ : chronic hypoxia (6 weeks). *: $p<0.05$ versus normoxia (unpaired t-test).

\section{$\mathrm{CH}$-induced structural remodelling}

There is a paucity of information concerning the effects of $\mathrm{CH}$ on respiratory muscle structure. MORTOLA and NASO [38] reported fibre transitions in diaphragm and limb muscle of rats after 9 months, but not 60 days, of $\mathrm{CH}$. Others have documented no effect of $\mathrm{CH}$ on adult diaphragm muscle fibres [15]. In the present study, the numerical density of MHC type 1 and type $2 \mathrm{~B}$ fibres increased. However, owing to changes in fibre $\mathrm{CSA}, \mathrm{CH}$ had no effect on MHC areal density in the diaphragm.

$\mathrm{CH}$ caused atrophy in fibres of the diaphragm. Atrophy or no change was noted in limb muscle fibres, but $\mathrm{CH}$ caused hypertrophy of fast $2 \mathrm{~A}$ and $2 \mathrm{X}$ fibres of the sternohyoid. In general, the literature from animal and human studies examining the effects of $\mathrm{CH}$ on fibre typology and morphology is quite unsettled. The mechanisms underlying the differential response of muscle fibres to $\mathrm{CH}$ are complex and largely unknown, and were not a major focus of the present study.

SDH activity was quantified as an index of oxidative capacity. It was found that $\mathrm{CH}$ had no effect on the SDH activity of diaphragm (or any muscle studied), suggesting that factors other than oxidative potential contribute to improved fatigue tolerance in the present model. However, it should be noted that the activity of other key oxidative enzymes that may have increased in the $\mathrm{CH}$ diaphragm were not measured.

It was speculated that the relative area of fibres expressing SERCA2 would increase in $\mathrm{CH}$ diaphragm. The present data indicate, however, that there was no significant difference between normoxic and $\mathrm{CH}$ muscles. This is consistent with findings in a rat model of emphysema [39]. SERCA2 activity was not measured, and this may have increased in $\mathrm{CH}$ diaphragm. However, half-relaxation time, which is
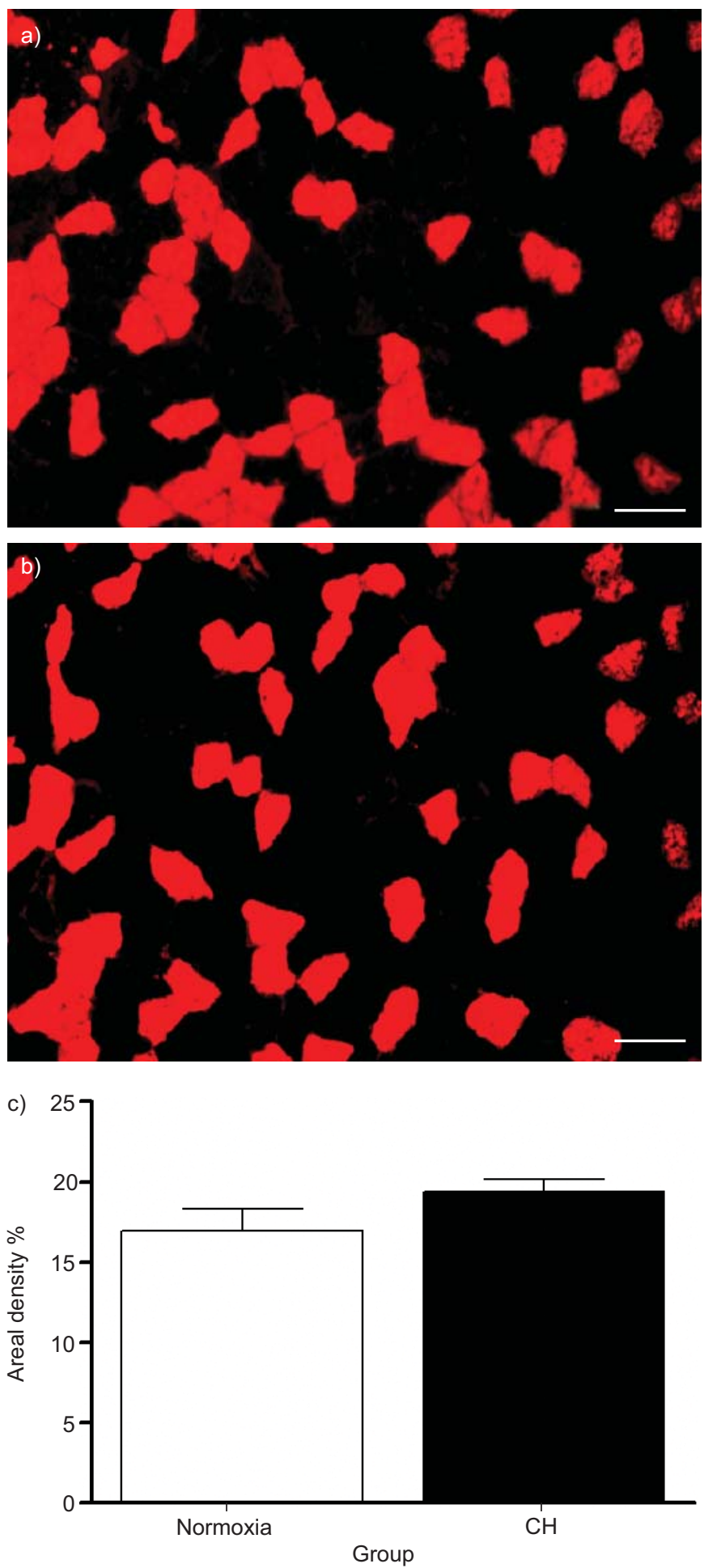

FIGURE 3. Diaphragm sarco/endoplasmic reticulum calcium-ATPase (SERCA) 2 immunohistochemistry. Representative images showing SERCA2-immunolabelled muscle fibres in rat diaphragm a) normoxic and b) chronic hypoxic $(\mathrm{CH})$. Scale bars $=100 \mu \mathrm{m}$. c) Group data ( $n=6$ for both groups) indicate that $\mathrm{CH}$ has no significant effect on the areal density of fibres expressing the SERCA2 isoform.

determined by SERCA activity, was unchanged in $\mathrm{CH}$ diaphragm. Thus SERCA pump content and activity are most probably unchanged. 


\begin{tabular}{ccc} 
TABLE 3 & $\begin{array}{l}\text { Succinate dehydrogenase }(\mathrm{SDH}) \text { and reduced } \\
\text { nicotinamide adenine dinucleotide phosphate } \\
\text { dehydrogenase (NADPHDH) histochemistry }\end{array}$ \\
\cline { 2 - 3 } & \multicolumn{2}{c}{ Optical density AU } \\
\hline SDH & NADPHDH \\
Sternohyoid & & \\
Normoxia & & $0.09 \pm 0.01$ \\
CH & $0.20 \pm 0.01$ & $0.08 \pm 0.01$ \\
Diaphragm & $0.20 \pm 0.01$ & $0.18 \pm 0.01$ \\
Normoxia & $0.59 \pm 0.04$ & $0.18 \pm 0.01$ \\
CH & $0.60 \pm 0.02$ & \\
\hline
\end{tabular}

Data are presented as mean \pm SEM ( $n=6-11$ per group). AU: arbitrary unit; $\mathrm{CH}$ : chronic hypoxia.

\section{$\mathrm{Na}^{+}, \mathrm{K}^{+}$-ATPase pump}

The present study is the first to show that $\mathrm{CH}$ increases $\mathrm{Na}^{+}, \mathrm{K}^{+}$-ATPase pump content in diaphragm muscle. It was found that $\mathrm{Na}^{+}, \mathrm{K}^{+}$-ATPase pump content increased by $\sim 24 \%$ in the $\mathrm{CH}$ diaphragm. $\mathrm{CH}$ also elevated pump content in the EDL, but elicited no change in the sternohyoid and soleus muscles of the same animals. A previous study reported a decrease in $\mathrm{Na}^{+}, \mathrm{K}^{+}$-ATPase pump content in human vastus lateralis on exposure to altitude for 3 weeks [40]. Interestingly, the same group found that, when exercise is performed in a hypoxic environment, pump content is also depressed [41]. It is difficult to reconcile why pump content is increased in some $\mathrm{CH}$ rat muscles but is decreased in hypoxic human muscle. This may relate to species differences or is perhaps dependent

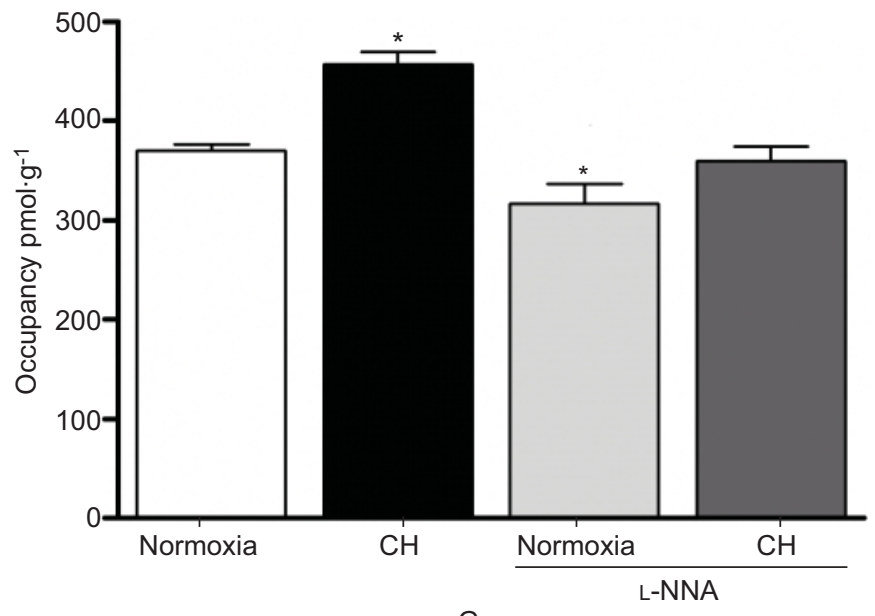

Group

FIGURE 4. Diaphragm muscle sodium-potassium ATPase $\left(\mathrm{Na}^{+}, \mathrm{K}^{+}-\mathrm{ATPase}\right)$ pump content. Data are presented as mean \pm SEM ouabain binding site occupancy (based on wet weight) in rats exposed to 6 weeks of normoxia or chronic hypoxia $(\mathrm{CH})$ with and without chronic nitric oxide synthase inhibition with $N^{\omega}$-nitro-L-arginine (L-NNA; 2 mM in drinking water throughout normoxia or $\mathrm{CH}$ treatment). Two-way ANOVA (hypoxia $\times$ drug) revealed significant effects of hypoxia and drug treatment. There was no significant interaction $(p=0.1)$ * : $p<0.05$ versus normoxia (Bonferroni post-hoc test; $\mathrm{n}=5-6$ per group).

\begin{tabular}{lccc} 
TABLE 4 & $\begin{array}{l}\text { Effect of chronic hypoxia }(\mathrm{CH})^{\#} \\
\text { ionic content }\end{array}$ & & \\
& $\mathbf{N a}^{+} \boldsymbol{\mu} \mathbf{m o l} \cdot \mathbf{g}^{-1}$ & $\mathbf{K}^{+} \boldsymbol{\mu} \mathbf{m o l} \cdot \mathbf{g}^{-1}$ & $\mathbf{C a}^{\mathbf{2 +}} \boldsymbol{\mu} \mathbf{m o l} \cdot \mathbf{g}^{-1}$ \\
\hline Normoxia & $31 \pm 5$ & $95 \pm 3$ & $1.5 \pm 0.1$ \\
$\mathbf{C H}$ & $31 \pm 2$ & $106 \pm 1^{*}$ & $1.7 \pm 0.3$ \\
\hline
\end{tabular}

Data are presented as mean \pm SEM (based on wet weight; $n=5-6$ ). ${ }^{\#}: 6$ weeks of hypoxia. *: $p<0.05$ versus normoxia (unpaired t-test).

upon differences in the duration and severity of hypoxic exposure, in addition to differences in the intrinsic structure of these muscles. A comprehensive assessment of structure in respiratory and limb muscles was performed for comparative purposes in order to determine whether $\mathrm{CH}$-induced structural remodelling were influenced by muscle activity. It could be argued that the increase in $\mathrm{Na}^{+}, \mathrm{K}^{+}$-ATPase pump content in $\mathrm{CH}$ diaphragm is secondary to the augmented activity of this muscle as a result of $\mathrm{CH}$-induced hyperventilation. This is in keeping with the repeated reports of training-induced upregulation of $\mathrm{Na}^{+}, \mathrm{K}^{+}$-ATPase pumps in skeletal muscle $[30,31]$. However, pump content was significantly elevated in EDL in the present study, suggesting that the increase was a result of a direct effect of hypoxia per se.

Since most fibres of the $\mathrm{CH}$ diaphragm atrophied, it could be argued that the increase in muscle surface area-to-volume ratio accounts for the increase in $\mathrm{Na}^{+}, \mathrm{K}^{+}$-ATPase pump content. In order to explore this further, whole-muscle and fibre-specific surface area-to-volume ratios were calculated and it was determined that $\mathrm{CH}$ causes a $13 \%$ increase (from a mean of 71,487 to $80,955 \mu \mathrm{m}^{2} \cdot \mathrm{mm}^{-3}$ ) in the area-to-volume ratio for whole diaphragm. Thus the increase in $\mathrm{Na}^{+}, \mathrm{K}^{+}$-ATPase pump

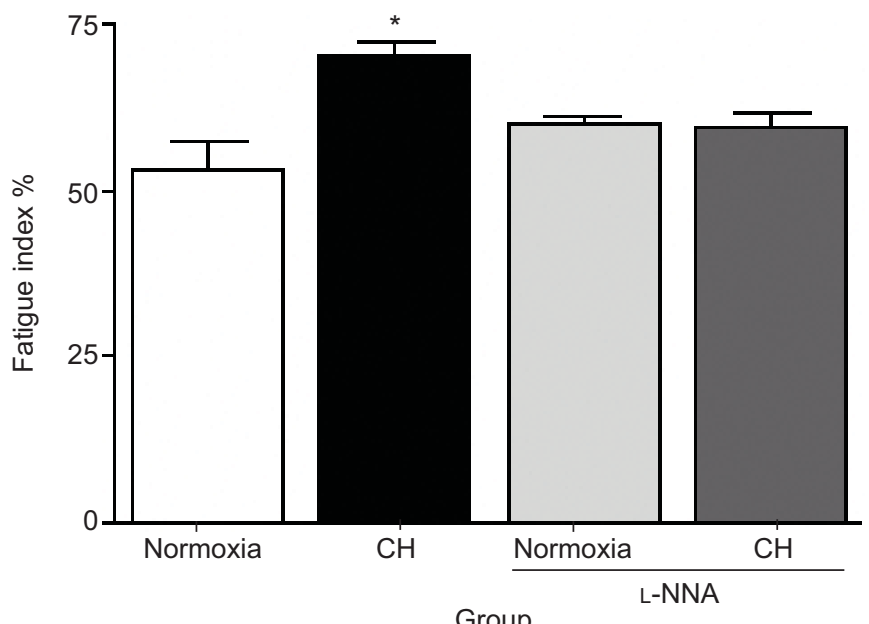

FIGURE 5. Effect of chronic hypoxia $(\mathrm{CH})$ on diaphragm muscle fatigue index Data are presented as mean \pm SEM in rats exposed to 6 weeks of normoxia or $\mathrm{CH}$ with and without chronic nitric oxide synthase inhibition with $N^{\omega}$-nitro-L-arginine ( $L$ NNA; $2 \mathrm{mM}$ in drinking water throughout normoxia or $\mathrm{CH}$ treatment). Two-way ANOVA (hypoxia $\times$ drug) revealed a significant effect of hypoxia, but not drug, treatment. The interaction was significant. *: $p<0.05$ versus normoxia (Bonferroni post-hoc test; $n=5-6$ per group). 
content in $\mathrm{CH}$ diaphragm (24\%) may be partly due to a concomitant increase in sarcolemmal area-to-volume ratio. It is interesting to note that the pump content increased by $11 \%$ in $\mathrm{CH}$ EDL, with no change in total muscle surface area-tovolume ratio $(-1.6 \%)$. Thus, when surface area-to-volume adjustments are accounted for, the effect of $\mathrm{CH}$ on respiratory and limb muscle $\mathrm{Na}^{+}, \mathrm{K}^{+}$-ATPase pump content is equivalent.

Increased $\mathrm{Na}^{+}, \mathrm{K}^{+}$-ATPase pump content may facilitate adaptation to a low oxygen environment by supporting the optimal muscle function essential for respiratory homeostasis. It would be most interesting to determine $\mathrm{Na}^{+}, \mathrm{K}^{+}$-ATPase pump content and activity in respiratory muscles from COPD patients.

\section{Role of $\mathrm{NO}$ in $\mathrm{CH}$-induced respiratory muscle remodelling}

NOS activity is regulated by muscle stimulation, mechanical activity, exercise and age, and can be up- or downregulated under a range of physiological and pathophysiological conditions. Skeletal muscle NOS activity undergoes significant upregulation during chronic exercise training in the rat and human. Exposure to hypobaric hypoxia for nearly 3 months in newborn rats was associated with an upregulation of endothelial NOS and neuronal (nNOS) levels and an increase in diaphragmatic NOS activity [42]. Chronic NOS blockade inhibits skeletal muscle adaptation to chronic endurance exercise, and results in a severe loss of walking speed in rats [43]. Furthermore, $\mathrm{nNOS}^{-1-}$ mice show decreased muscle endurance [44], and diaphragm dysfunction is exacerbated following lipopolysaccharide challenge in $\mathrm{nNOS}^{-/-}$mice compared to wild-type controls [45]. Studies of various tissues have shown that NOS expression and activity are regulated by hypoxia, but the effects of chronic NOS blockade on $\mathrm{CH}$ muscle function are not known. It was speculated that chronic NOS inhibition would attenuate or prevent $\mathrm{CH}$ diaphragm remodelling. That is, we reasoned that $\mathrm{CH}$-induced respiratory muscle adaptation has a structural basis and that NO is critically involved. It was found that chronic NOS inhibition significantly decreased diaphragm $\mathrm{Na}^{+}, \mathrm{K}^{+}$-ATPase pump content in normoxic and $\mathrm{CH}$ rats. Of interest, $\mathrm{CH}+\mathrm{L}-\mathrm{NNA}$ diaphragm surface area-tovolume ratio $\left(81,096 \mu \mathrm{m}^{2} \cdot \mathrm{mm}^{-3}\right)$ was equivalent to that of $\mathrm{CH}$ diaphragm, but $\mathrm{Na}^{+}, \mathrm{K}^{+}$-ATPase pump content was decreased to control levels (fig. 4). It is, therefore, apparent that NOS inhibition downregulates respiratory muscle $\mathrm{Na}^{+}, \mathrm{K}^{+}$-ATPase pump content independent of surface area-to-volume adjustments. NOS inhibition completely suppressed increased fatigue tolerance in $\mathrm{CH}$ diaphragm, implicating $\mathrm{NO}$ in functional remodelling of $\mathrm{CH}$ diaphragm. The present study provides novel data indicating that $\mathrm{NO}$ has a regulatory role in modulating $\mathrm{Na}^{+}, \mathrm{K}^{+}$-ATPase pump content in rat respiratory muscles.

\section{Summary and conclusion}

Skeletal muscles, including the striated muscles of breathing, demonstrate a remarkable capacity to respond to physiological and environmental challenges. During hypoxic adaptation, the respiratory muscles face unique challenges that must be overcome in order to ensure maintenance of homeostasis. Our translational model highlights the fact that hypoxic signalling can serve as a trigger of molecular and cellular adjustments that ultimately shape respiratory muscle performance. The present study demonstrates that $\mathrm{CH}$ is associated with increased $\mathrm{Na}^{+}, \mathrm{K}^{+}$-ATPase pump content in diaphragm concomitant with increased muscle endurance. Chronic NOS inhibition reduced diaphragm $\mathrm{Na}^{+}, \mathrm{K}^{+}$-ATPase pump content and prevented a $\mathrm{CH}$-induced increase in diaphragm endurance. This study provides novel insight into mechanisms involved in $\mathrm{CH}$-induced muscle remodelling. The results may be of relevance to respiratory disorders characterised by $\mathrm{CH}$, such as COPD, in which respiratory muscle remodelling is known to occur.

\section{SUPPORT STATEMENT}

This study was funded by the Health Research Board (Dublin, Ireland; grant RP/2006/140) and University College Dublin (UCD) School of Medicine and Medical Science (Health Sciences Centre, UCD, Dublin, Ireland) Translational Medicine PhD Programme. J. Carberry was in receipt of a UCD School of Medicine and Medical Science scholarship. R.A. O'Connell is funded by the Irish Research Council for Science, Engineering and Technology (Dublin, Ireland).

\section{STATEMENT OF INTEREST}

None declared.

\section{ACKNOWLEDGEMENTS}

We are grateful to T. Clausen (University of Aarhus, Aarhus, Denmark) for critical appraisal of an early draft of the present manuscript. We also thank the anonymous reviewers of the manuscript for several informed suggestions, and are especially grateful to one reviewer for drawing our attention to the issue of surface area-tovolume ratio adjustment in remodelled muscle.

\section{REFERENCES}

1 Deveci D, Marshall JM, Egginton S. Chronic hypoxia induces prolonged angiogenesis in skeletal muscles of rat. Exp Physiol 2002; 87: 287-291.

2 Snyder GK, Wilcox EE, Burnham EW. Effects of hypoxia on muscle capillarity in rats. Respir Physiol 1985; 62: 135-140.

3 Abdelmalki A, Fimbel S, Mayet-Sornay MH, et al. Aerobic capacity and skeletal muscle properties of normoxic and hypoxic rats in response to training. Pflugers Arch 1996; 431: 671-679.

4 Bigard AX, Sanchez H, Birot O, et al. Myosin heavy chain composition of skeletal muscles in young rats growing under hypobaric hypoxia conditions. J Appl Physiol 2000; 88: 479-486.

5 Faucher M, Guillot C, Marqueste T, et al. Matched adaptations of electrophysiological, physiological, and histological properties of skeletal muscles in response to chronic hypoxia. Pflugers Arch 2005; 450: 45-52.

6 Green HJ, Sutton JR, Cymerman A, et al. Operation Everest II: adaptations in human skeletal muscle. J Appl Physiol 1989; 66: 2454-2461.

7 Hirofuji C, Ishihara A, Itoh K, et al. Fibre type composition of the soleus muscle in hypoxia-acclimatised rats. J Anat 1992; 181: 327-333.

8 Ishihara A, Itoh K, Oishi $\mathrm{Y}$, et al. Effects of hypobaric hypoxia on histochemical fibre-type composition and myosin heavy chain isoform component in the rat soleus muscle. Pflugers Arch 1995; 429: 601-606.

9 Itoh K, Itoh M, Ishihara A, et al. Influence of 12 weeks of hypobaric hypoxia on fibre type composition of the rat soleus muscle. Acta Physiol Scand 1995; 154: 417-418.

10 MacDougall JD, Green HJ, Sutton JR, et al. Operation Everest II: structural adaptations in skeletal muscle in response to extreme simulated altitude. Acta Physiol Scand 1991; 142: 421-427.

11 Desplanches D, Hoppeler H, Tuscher L, et al. Muscle tissue adaptations of high-altitude natives to training in chronic hypoxia or acute normoxia. J Appl Physiol 1996; 81: 1946-1951. 
12 Howald H, Pette D, Simoneau JA, et al. Effect of chronic hypoxia on muscle enzyme activities. Int J Sports Med 1990; 11: S10-S14.

13 Jammes Y, Zattara-Hartmann MC, Badier M. Functional consequences of acute and chronic hypoxia on respiratory and skeletal muscles in mammals. Comp Biochem Physiol A Physiol 1997; 118: 15-22.

14 Kass LJ, Bazzy AR. Chronic hypoxia modulates diaphragm function in the developing rat. J Appl Physiol 2001; 90: 2325-2329.

15 El-Khoury R, O'Halloran KD, Bradford A. Effects of chronic hypobaric hypoxia on contractile properties of rat sternohyoid and diaphragm muscles. Clin Exp Pharmacol Physiol 2003; 30: 551-554.

16 Shiota S, Okada T, Naitoh $\mathrm{H}$, et al. Hypoxia and hypercapnia affect contractile and histological properties of rat diaphragm and hind limb muscles. Pathophysiology 2004; 11: 23-30.

17 Doucet M, Debigare R, Joanisse DR, et al. Adaptation of the diaphragm and the vastus lateralis in mild-to-moderate COPD. Eur Respir J 2004; 24: 971-979.

18 Levine S, Gregory C, Nguyen T, et al. Bioenergetic adaptation of individual human diaphragmatic myofibers to severe COPD. J Appl Physiol 2002; 92: 1205-1213.

19 Levine S, Kaiser L, Leferovich J, et al. Cellular adaptations in the diaphragm in chronic obstructive pulmonary disease. $N$ Engl $J$ Med 1997; 337: 1799-1806.

20 Levine S, Nguyen T, Kaiser LR, et al. Human diaphragm remodeling associated with chronic obstructive pulmonary disease: clinical implications. Am J Respir Crit Care Med 2003; 168: 706-713.

21 Mercadier JJ, Schwartz K, Schiaffino S, et al. Myosin heavy chain gene expression changes in the diaphragm of patients with chronic lung hyperinflation. Am J Physiol 1998; 274: L527-L534.

22 Stubbings AK, Moore AJ, Dusmet M, et al. Physiological properties of human diaphragm muscle fibres and the effect of chronic obstructive pulmonary disease. J Physiol 2008; 586: 2637-2650.

23 Mador MJ, Kufel TJ, Pineda LA, et al. Diaphragmatic fatigue and high-intensity exercise in patients with chronic obstructive pulmonary disease. Am J Respir Crit Care Med 2000; 161: 118-123.

24 Polkey MI, Kyroussis D, Hamnegard CH, et al. Diaphragm performance during maximal voluntary ventilation in chronic obstructive pulmonary disease. Am J Respir Crit Care Med 1997; 155: 642-648.

25 Polkey MI, Kyroussis D, Keilty SE, et al. Exhaustive treadmill exercise does not reduce twitch transdiaphragmatic pressure in patients with COPD. Am J Respir Crit Care Med 1995; 152: 959-964.

26 Levine S, Nguyen T, Friscia M, et al. Parasternal intercostal muscle remodeling in severe chronic obstructive pulmonary disease. J Appl Physiol 2006; 101: 1297-1302.

27 Sanchez J, Brunet A, Medrano G, et al. Metabolic enzymatic activities in the intercostal and serratus muscles and in the latissimus dorsi of middle-aged normal men and patients with moderate obstructive pulmonary disease. Eur Respir J 1988; 1: 376-383.

28 Aubier M, Viires N. Calcium ATPase and respiratory muscle function. Eur Respir J 1998; 11: 758-766.
29 Nguyen T, Rubinstein NA, Vijayasarathy C, et al. Effect of chronic obstructive pulmonary disease on calcium pump ATPase expression in human diaphragm. J Appl Physiol 2005; 98: 2004-2010.

30 Clausen T, van Hardeveld C, Everts ME. Significance of cation transport in control of energy metabolism and thermogenesis. Physiol Rev 1991; 71: 733-744.

31 Clausen $\mathrm{T}$. $\mathrm{Na}^{+}-\mathrm{K}^{+}$pump regulation and skeletal muscle contractility. Physiol Rev 2003; 83: 1269-1324.

32 Nielsen $\mathrm{OB}$, Clausen T. Regulation of $\mathrm{Na}^{+}-\mathrm{K}^{+}$pump activity in contracting rat muscle. J Physiol 1997; 503: 571-581.

33 Nørgaard A, Kjeldsen K, Hansen O, et al. A simple and rapid method for the determination of the number of ${ }^{3} \mathrm{H}$-ouabain binding sites in biopsies of skeletal muscle. Biochem Biophys Res Commun 1983; 111: 319-325.

34 McKenna MJ, Gissel H, Clausen T. Effects of electrical stimulation and insulin on $\mathrm{Na}^{+}-\mathrm{K}^{+}$-ATPase $\left(\left[{ }^{3} \mathrm{H}\right]\right.$ ouabain binding) in rat skeletal muscle. J Physiol 2003; 547: 567-580.

35 Punkt K, Naupert A, Wellner M, et al. Nitric oxide synthase II in rat skeletal muscles. Histochem Cell Biol 2002; 118: 371-379.

36 Punkt K, Fritzsche M, Stockmar C, et al. Nitric oxide synthase in human skeletal muscles related to defined fibre types. Histochem Cell Biol 2006; 125: 567-573.

$37 \mathrm{Yu} \mathrm{Z}$, Li P, Zhang M, et al. Fiber type-specific nitric oxide protects oxidative myofibers against cachectic stimuli. PLoS One 2008; 3: e2086.

38 Mortola JP, Naso L. Electrophoretic analysis of contractile proteins of the diaphragm in chronically hypoxic rats. Am J Physiol 1995; 269: L371-L376.

39 Kim DK, Zhu J, Kozyak BW, et al. Myosin heavy chain and physiological adaptation of the rat diaphragm in elastase-induced emphysema. Respir Res 2003; 4: 1-10.

40 Green $\mathrm{H}$, Roy B, Grant S, et al. Downregulation in muscle $\mathrm{Na}^{+}-\mathrm{K}^{+}$ATPase following a 21-day expedition to 6,194 m. J Appl Physiol 2000; 88: 634-640.

41 Green H, MacDougall J, Tarnopolsky M, et al. Downregulation of $\mathrm{Na}^{+}-\mathrm{K}^{+}$-ATPase pumps in skeletal muscle with training in normobaric hypoxia. J Appl Physiol 1999; 86: 1745-1748.

42 Javeshghani D, Sakkal D, Mori M, et al. Regulation of diaphragmatic nitric oxide synthase expression during hypobaric hypoxia. Am J Physiol Lung Cell Mol Physiol 2000; 279: L520-L527.

43 Wang MX, Murrell DF, Szabo C, et al. Nitric oxide in skeletal muscle: inhibition of nitric oxide synthase inhibits walking speed in rats. Nitric Oxide 2001; 5: 219-232.

44 Percival JM, Anderson KN, Gregorevic P, et al. Functional deficits in nNOS $\mu$-deficient skeletal muscle: myopathy in nNOS knockout mice. PLoS One 2008; 3: e3387.

45 Comtois AS, Barreiro E, Huang PL, et al. Lipopolysaccharideinduced diaphragmatic contractile dysfunction and sarcolemmal injury in mice lacking the neuronal nitric oxide synthase. Am J Respir Crit Care Med 2001; 163: 977-982. 